Araştırma Makalesi (Research Article)

Olcay ARABACl ${ }^{1}$

H. Eda TOKUL2

Neval Gül ÖĞRETMEN ${ }^{1}$

Emine BAYRAM ${ }^{2}$

\author{
${ }^{1}$ Adnan Menderes Üniversitesi, Ziraat Fakültesi, \\ Tarla Bitkileri Bölümü, 09970 İzmir /Türkiye \\ ${ }^{2}$ Ege Üniversitesi, Ziraat Fakültesi, Tarla Bitkileri \\ Bölümü, 35100 İzmir /Türkiye \\ e-posta:oarabaci@adu.edu.tr
}

Anahtar Sözcükler:

Coridothymus capitatus L., kekik, diurnal varyabilite, uçucu yağ, verim

Key Words:

Coridothymus capitatus L., thyme, diurnal variation, essential oil, yield
Ege Üniv. Ziraat Fak. Derg., 2015, 52 (2):141-150

ISSN $1018-8851$

\section{Doğal Yayılış Gösteren Coridothymus capitatus L. Genotiplerinde Diurnal Varyabilitenin Verim ve Kaliteye Etkisi}

\author{
The Effect of Diurnal Variability on Yield and Quality in \\ Naturally Grown Coridothymus capitatus L. Genotypes
}

Alıış (Received): 23.10.2014 Kabul tarihi (Accepted): 12.03.2015

\section{ÖZET} kdeniz havzasının tipik doğal bitkilerinden olan Coridothymus capitatus L.
Batı ve Güney Anadolu'da maki açıklıkları ve deniz kıyısı friganası içinde
yaygın olan saf topluluklar oluşturur. Aydın ilinde doğadan toplanan kekik
türlerinden biri olan Coridothymus capitatus L. bitkisinde uçucu yağ oranının en
yüksek olduğu gelişme döneminde (tam ççeklenme) gün içindeki en uygun
hasat saatinin (diurnal varyabilite) belirlenmesi bu çalışmanın amacını
oluşturmaktadır. Çalışma 2012 yılında, ADÜ Güney Yerleşkesinde doğal yayılış
gösteren Coridothymus capitatus L. genotiplerinde yürütülmüştür. Fenotipik
olarak seçilip numaralandırılan 25 genotipte bir günlük sürede hasat sürecini
kapsayan saat $06: 00-20: 00$ arasında yapılan toplam 8 hasat ile uçucu yağ oranı
bakımından hem genotipler hem de hasat saatleri arasında büyük bir
varyasyonun olduğu belirlenmiş ve diurnal varyabititenin varlığı ortaya
konmuştur. Coridothymus capitatus L. genotiplerinin saat $06: 00$ hasadında
\%4.99 ile en yüksek uçucu yağ oranına sahip olduğu, gün içerisindeki sıcaklığın
en yüksek ve oransal nem değerinin en düşük olduğu saatlerde \%4.51 ile en
düşük ortalama uçucu yağ oranının olduğu tespit edilmiştir. Uçucu yağ oranı en
yüksek olan dört genotipte yapılan bileşen analizi ile incelenen dört genotipin
ana bileşeninin karvakrol olduğu ve oranının \%42.87-87.38 arasında değiştiği
belirlenmiştir.

\section{ABSTRACT}

-oridothymus capitatus L., a characteristic plant of the Mediterranean basin, arranges into pure populations that are prevalent within maquis spreads and among the seashore frigana in Western and Southern regions of the Anatolian peninsula. The present study aims to determine the optimal time of harvest based on diurnal variation for Coridothymus capitatus L., a thyme species picked from the wild within the province of Aydin, during full bloom when the essential oil content of the plant is at its highest. The study was conducted on the Coridothymus capitatus $L$. genotypes that were prevalent in the Southern Campus of Adnan Menderes University in 2012. The volatile oil content determined form 8 different harvests collected throughout the harvesting period of 06:00-20:00 within a single day for the 25 different genotypes that were selected and numerically designated based on their phenotypic characteristics revealed a broad range of variation both among different genotypes and among different times of harvesting establishing the presence of diurnal variation. The highest essential oil content was determined as $4.99 \%$ during the $06: 00$ harvest of Coridothymus capitatus $L$. and the lowest essential oil content of $\mathbf{4 . 5 1 \%}$ was determined during the period of highest temperature and lowest humidity. Carvacrol was determined as the main constituent of all four genotypes that had the highest volatile oil ratio under investigation and the content was determined to vary in the range of 42.87$\mathbf{8 7 . 3 8 \%}$. 


\section{GíRiş}

Coridothymus capitatus $\mathrm{L}$. Labiatae familyasına ait çok yıllık, aromatik bir bitkidir. Uluslararası ticarette "Spanish oregano" İspanyol kekiği (Özek ve ark. 1995; Baydar ve ark.,1999; Arabacı ve ark., 2012) olarak bilinen bitki, beyaz kekik Türkçe adıyla, bal kekiği, kara kekik vd. yöresel adlarıyla bilinmektedir (Zeybek ve Zeybek 1994; Seçmen ve ark., 1995; Anonim, 2012; Arabacı ve ark., 2012). Akdeniz havzasının tipik doğal bitkilerinden olan Coridothymus capitatus L. Batı ve Güney Anadolu'da; Aydın, Balıkesir, Çanakkale, İzmir ve Muğla illerinde çoğunlukla da maki açıklıkları ve deniz kıyısı friganası içinde yaygın olan saf topluluklar oluşturur (Davis, 1982; Diri, 2006; Anonim, 2012).

Halk hekimliğinde mide ağrısı, öksürük ve soğuk algınlığında infüzyon şeklinde kullanılmaktadır (Sezik ve Yeşilada, 1999). Bitkiden aromatik, antibakteriyal, antifungal ve antioksidan olarak da yararlanılmaktadır (Gören, 2003).

Coridothymus capitatus L. bitkisinin karakteristik kokusu içerdiği uçucu yağdan kaynaklanmaktadır. Bitkinin uçucu yağ oranının \%0.4-6.6 arasında değiştiği bildirilmiştir (Özek ve ark., 1995; Baydar ve ark., 1999; Baytop, 1999; Skoula ve Grayer 2005; Diri, 2006; Arabacı ve ark., 2012). Bitkinin yapraklarından elde edilen uçucu yağı parfümeride, sabun yapımında, ağız temizleyici ve iyileştirici olarak pek çok alanda kullanılmaktadır. Çiçekleri bal arıları için oldukça çekici ve nektar bakımından zengindir (Polunin ve Huxley, 1987; Bown, 1995). Ayrıca uçucu yağının ve kimyasal kompozisyonunun patatesin depolanması üzerine antibakteriyal etki gösterdiği saptanmıştır (Vokou ve ark., 1993).

Sekonder metabolitler genotipik ve ekolojik faktörlere bağı olarak oluşmaktadır. Aynı zamanda agronomik uygulamalarla da bu oluşuma katkı sağlanmaktadır. Doğal yayılış gösteren bitkilerde verim ve kalite açısından büyük bir değişkenlik söz konusudur. Tıbbi bitki populasyonlarının karakterizasyonu bu açıdan önemlidir. Bitki toplayıcılığının yaygın olduğu tıbbi bitkilerde toplama zamanının tespit edilmesi var olan kalitenin iyileştirilmesi açısından üzerinde durulması gereken konulardan biridir.

Bölgemizde doğadan toplanan kekik türlerinden biri olan Coridothymus capitatus L. bitkisinde uçucu yağ oranının en yüksek olduğu gelişme döneminde gün içindeki en uygun hasat saati (diurnal varyabilite)' nin belirlenmesi bu çalışmanın amacını oluşturmaktadır.

\section{MATERYAL ve YÖNTEM}

Bu çalışma, 2012 vejetasyon yılı içerisinde Aydın ekolojik koşullarında Adnan Menderes Üniversitesi (ADÜ) Güney Yerleşkesi'nde doğal yayılış gösteren Coridothymus capitatus L. genotipleri üzerinde yürütülmüştür. Aydın ili konum olarak; $37^{\circ} 30^{\prime}$ ve $38^{\circ}$ $03^{\prime}$ kuzey enlemleriyle, $27^{\circ} 00^{\prime}$ ve $28^{\circ} 57^{\prime}$ doğu boylamları arasındadır. Araştırmanın yürütüldüğü ADÜ Güney Yerleşkesi ise Aydın iline $18 \mathrm{~km}$ mesafede $37^{\circ}$ $44^{\prime}$ ve $37^{\circ} 49^{\prime}$ kuzey enlemleri ile $27^{\circ} 43^{\prime}$ ve $27^{\circ} 50^{\prime}$ doğu boylamları arasında bulunmaktadır.

Aydın ili Akdeniz Flora bölgesinde yer almakta ve ılıman Akdeniz ikliminin etkisi altında bulunmaktadır. Yörede hüküm süren Akdeniz iklimi sebebiyle, doğadaki bitkiler kış bitimi, erken ilkbaharda uyanmaktadırlar. Araştırmanın yürütüldüğü bölgenin 2012 yılı Temmuz ayına ait uzun yıllar (1975-2010) ortalamasına göre yıllık toplam yağış $3,4 \mathrm{~mm}$, yıllık ortalama sıcaklık $28,3^{\circ} \mathrm{C}$ ve oransal nem $\% 50,6$ olarak kaydedilmiştir. Denemenin yürütüldüğü fenolojik dönem olan tam çiçeklenme döneminde bitkilerin hasat saatlerine ilişkin ortalama sıcaklık, oransal nem ve global radyasyon değerleri Çizelge 1 'de verilmiştir. Çizelge $1^{\prime}$ in incelenmesinden de anlaşılacağı gibi, hasat saatlerine göre gün doğumu ve gün batımı arasındaki bir günlük süre içerisinde sıcaklığın 21,6$40,3^{\circ} \mathrm{C}$, oransal nemin $\% 22-77$ ve global radyasyonun $0-417 \mathrm{w} / \mathrm{m}^{2}$ arasında değiştiği belirlenmiştir.

Çizelge 1. Denemenin yürütüldüğü güne ait bazı iklim verileri

Table 1. Some climate data for the day which the trial was conducted

\begin{tabular}{|c|c|c|c|}
\hline Hasat Saatleri & $\begin{array}{c}\text { Ortalama Sicaklık } \\
\left({ }^{\circ} \mathrm{C}\right)\end{array}$ & $\begin{array}{c}\text { Oransal Nem } \\
(\%)\end{array}$ & $\begin{array}{c}\text { Global Radyasyon } \\
\left(\mathrm{W} / \mathrm{m}^{2}\right)\end{array}$ \\
\hline $06: 00$ & 21,55 & 77 & 20 \\
\hline 08:00 & 27,45 & 56 & 206 \\
\hline $10: 00$ & 32,80 & 38 & 339 \\
\hline $12: 00$ & 36,81 & 27 & 417 \\
\hline $14: 00$ & 38,74 & 26 & 395 \\
\hline $16: 00$ & 40,29 & 22 & 289 \\
\hline $18: 00$ & 37,67 & 28 & 148 \\
\hline $20: 00$ & 36,02 & 27 & 0 \\
\hline
\end{tabular}

*Imetos 2012 yılı kayıtları ve Aydın Meteoroloji Bölge Müdürlüğüne ait veriler 
Çalışma materyalini Coridothymus capitatus L. populasyonu içerisinde iri habitus oluştur-duğu belirlenen, daha önceki çalışmamızda kullanılan genotiplerden farklı olan ve önceden numaralandırılmış 25 genotip oluşturmuştur. Hasat işlemi bitkilerin tam çiçeklenme dönemine geldiği 16 Temmuz 2012 tarihinde gerçekleştirilmiş̧ir. Fenotipik olarak seçilerek numaralandırılan bitkilerde sabah güneşin doğuşu ile batışı arasında geçen süre içerisindeki morfolojik, verim ve kaliteye yönelik varyasyonu belirlemek amacıyla saat 06:00, 08:00, 10:00, 12:00, 14:00, 16:00, 18:00 ve $20: 00^{\prime}$ de olmak üzere iki saat aralıklarla toplam 8 hasat yapılmıştır. Hasat öncesinde genotiplerin bitki boyu $(\mathrm{cm})$ ve çiçek boyu $(\mathrm{cm})$ ölçülmüş, taze çiçek ve yeşil herba örnekleri alınmıştır.

Her hasat saatinde incelenen 25 genotipin her birinden yaklaşık $100 \mathrm{~g}$ olacak şekilde yeşil herba örneği alınmış, kurutma öncesi her örnek tartılarak yeşil herba ağırlığı belirlenmiş, örnekler oda sıcaklığında kurutulduktan sonra tartılmış ve yüzdeleri belirlenmiştir. Her bir genotip için belirlenen drog herba oranlarından yararlanılarak yapılan istatistiksel değerlendirme sonucu denemede incelenen hasat saatlerinin her biri için minimum, maksimum ve ortalama değerler hesaplanmıştır.

Bitki örneklerinde kalite analizleri E.Ü.Z.F. Tarla Bitkileri Bölümü Tıbbi ve Aromatik Bitkiler Laboratuvarında gerçekleştirilmiştir. Farklı hasat saatleri ve genotiplere ait uçucu yağ oranları hava kurusu $10 \mathrm{~g}$ drog herba (yaprak+çiçek) örneklerinde iki paralel olacak şekilde su distilasyonu yöntemine göre Neoclevenger aparatı ile volumetrik olarak belirlenmiştir. Hasat edilen bitkilerin uçucu yağ oranı kuru madde üzerinden mililitre/100g (\%) olarak verilmiştir (Wichtl, 1971).

Uçucu yağ oranlarının belirlenmesinde Gaz Kromotografisi (GC) yöntemi kullanıımıştır. Uçucu yağ bileşim analizi, Agilent 6890 N Kapiler Kolonlu Gaz Kromotografi cihazı ile belirlenmiştir. Çalışmada kullanılan GC koşulları ise şu şekildedir. Kullanılan kolon: DB-WAXETR Kapilar Kolon, Kolon uzunluğu: $30 \mathrm{~m}$, $45^{\circ} \mathrm{C}: 2 \mathrm{dk}, 45-250^{\circ} \mathrm{C}: 3^{\circ} / \mathrm{min}$., $250^{\circ} \mathrm{C}: 34 \mathrm{dk}$, dedektör sıcaklığı: $250^{\circ} \mathrm{C}$, enjektör sıcaklığı: $250^{\circ} \mathrm{C}$, taşıyııı gaz: helyum, gazın akış hızı: $150^{\circ} \mathrm{C}^{\prime}$ de 25 /dakikadır.

Elde edilen verilerin istatistiksel analizi TARIST paket programı kullanılarak yapılmıştır (Açıkgöz ve ark., 1994).

\section{BULGULAR ve TARTIŞMA}

Doğal yayılış gösteren Coridothymus capitatus L. genotiplerinin alındığı koordinatlar ve yükseltiler Çizelge 2'de verilmiştir. Çizelge 2 incelendiğinde çalışma alanında yer alan popülasyonun $66-86 \mathrm{~m}$ arasında bulunduğu görülmektedir. Coridothymus capitatus L. bitkisinin 1-1400 m arasındaki yükseltilerde doğal yayılış gösterdiği bildirilmiştir (Davis, 1982).

\begin{tabular}{|c|c|c|c|c|c|}
\hline Bitki No & Koordinat & Rakım (m) & Bitki No & Koordinat & Rakım (m) \\
\hline 1 & $0566418-4179251$ & 77 & 14 & $0566376-4179467$ & 67 \\
\hline 2 & 0566419-4179247 & 78 & 15 & 0566387-4179477 & 71 \\
\hline 3 & 0566409-4179238 & 78 & 16 & $0566400-4179451$ & 72 \\
\hline 4 & 0566412-4179229 & 78 & 17 & 0566408-4179451 & 73 \\
\hline 5 & 0566423-4179237 & 80 & 18 & $0566412-4179447$ & 73 \\
\hline 6 & $0566425-4179229$ & 81 & 19 & 0566398-4179468 & 72 \\
\hline 7 & 0566435-4179216 & 83 & 20 & $0566400-4179476$ & 71 \\
\hline 8 & 0566427-4179208 & 86 & 21 & 0566407-4179469 & 73 \\
\hline 9 & 0566423-4179210 & 86 & 22 & $0566437-4179433$ & 73 \\
\hline 10 & 0566414-4179212 & 85 & 23 & 0566435-4179220 & 83 \\
\hline 11 & $0566407-4179224$ & 80 & 24 & 0566435-4179206 & 83 \\
\hline 12 & 0566402-4179239 & 76 & 25 & 0566427-4179186 & 86 \\
\hline 13 & $0566375-4179464$ & 66 & & & \\
\hline
\end{tabular}

Coridothymus capitatus $\mathrm{L}$. populasyonu içerisinde yer alan 25 genotipte tam çiçeklenme döneminde bir günlük süre içerisinde iki saat aralıklarla yapılan hasatlarda incelenen genotiplerin morfolojik ve verim özelliklerine ait bazı istatistiksel değerler Çizelge 3'te verilmiştir. Deneme materyalini oluşturan genotiplerin ortalama bitki boyunun $44.5 \mathrm{~cm}$ ve ortalama çiçek başağı boyunun $1.2 \mathrm{~cm}$ olduğu belirlenmiştir. Aynı çizelgeden ortalama tek çiçek başağı drog ağırlığının $1.35 \mathrm{~g}$, tek bitki yeşil herba veriminin $770 \mathrm{~g}$ ve tek bitki drog herba veriminin de $501 \mathrm{~g}$ olduğu izlenebilmektedir. Incelenen morfolojik ve verim özellikleri bakımından genotipler arasında geniş varyasyonun olduğu belirlenmiştir. 
Çizelge 3. Coridothymus capitatus L. genotiplerinde morfolojik ve verim özelliklerine ilişkin bazı istatistiksel değerler

Table 3. Some statistical values for some morphological and yield traits of coridothymus capitatus L. genotypes

\begin{tabular}{|c|c|c|c|c|c|c|c|c|}
\hline İncelenen Özellikler & Genotip Sayısı & Min. & Max. & Ort. & Varyans & Standart Sapma & Sx & CV \\
\hline Bitki Boyu (cm) & 25 & 35.00 & 54.00 & 44.48 & 21.8433 & 4.6737 & 0.9347 & 10.5074 \\
\hline $\begin{array}{l}\text { Çiçek Başağı } \\
\text { Boyu }(\mathrm{cm}) \\
\end{array}$ & 25 & 0.89 & 1.49 & 1.18 & 0.0301 & 0.1735 & 0.0347 & 14.7319 \\
\hline $\begin{array}{l}\text { Tek Çiçek Başağı Drog } \\
\text { Ağırlığı (g) }\end{array}$ & 25 & 1.09 & 1.98 & 1.35 & 0.0771 & 0.2776 & 0.0555 & 20.5263 \\
\hline $\begin{array}{l}\text { Tek Bitki Yeşil Herba } \\
\text { Verimi (g) }\end{array}$ & 25 & 655 & 939 & 769.68 & 5026.5600 & 70.8982 & 14.1796 & 9.2114 \\
\hline $\begin{array}{l}\text { Tek Bitki Drog Herba } \\
\text { Verimi }(g)\end{array}$ & 25 & 436 & 599 & 501.28 & 1835.7100 & 42.8452 & 8.5690 & 8.5472 \\
\hline
\end{tabular}

Hasat saatlerine göre genotiplerin drog olmadığı ve bu süre içerisinde ortalama değerlerin herba oranlarındaki değişime ilişkin değerlerin \%61.3 - 68.3 arasında olduğu saptanmıştır. Buna yer aldığı Çizelge 4 incelendiğinde ise, güneşin göre diurnal varyabilitenin verimi etkilemediği, doğuşu ve batışı arasında geçen sürede drog oluşan farklılığının genotiplerden kaynaklandığı herba oranını etkileyen önemli bir farklılığın söylenebilir.

Çizelge 4. Hasat saatlerine göre Coridothymus capitatus L. genotiplerinde drog herba oranına (\%) ilişkin bazı istatistiksel değerler Table 4. Some harvest-hour based statistical values for drug herbage rate (\%) in coridothymus capitatus L. genotypes

\begin{tabular}{|c|c|c|c|c|c|c|c|c|}
\hline Hasat Saatleri & Genotip Sayısı & Min. & Max. & Ort. & Varyans & Standart Sapma & Sx & CV \\
\hline 06:00 & 25 & 52.7 & 70.9 & 62.1 & 19.8482 & 4.4551 & 0.8910 & 7.1700 \\
\hline 08:00 & 25 & 54.6 & 69.0 & 62.0 & 13.7983 & 3.7146 & 0.7429 & 5.9905 \\
\hline $10: 00$ & 25 & 58.4 & 74.7 & 67.7 & 15.2429 & 3.9042 & 0.7808 & 5.7666 \\
\hline $12: 00$ & 25 & 60.5 & 74.7 & 68.3 & 13.5954 & 3.6872 & 0.7374 & 5.3982 \\
\hline $14: 00$ & 25 & 54.3 & 73.1 & 65.1 & 22.3550 & 4.7281 & 0.9456 & 7.2628 \\
\hline $16: 00$ & 25 & 55.0 & 72.3 & 65.1 & 12.4618 & 3.5301 & 0.7060 & 5.4266 \\
\hline $18: 00$ & 25 & 61.4 & 74.0 & 66.0 & 7.2289 & 2.6887 & 0.5377 & 4.0747 \\
\hline $20: 00$ & 25 & 51.0 & 72.1 & 61.3 & 21.9754 & 4.6878 & 0.9376 & 7.6508 \\
\hline
\end{tabular}

Coridothymus capitatus L. genotiplerinde uçucu yağ oranlarının diurnal varyabilitesi Çizelge 5 ve Şekil 1'de verilmiştir. Hasat sürecini kapsayan 06:00 ile 20:00 saatleri arasında uçucu yağ oranı bakımından hem genotipler hem de hasat saatleri arasında büyük bir varyasyonun olduğu Çizelge 5'de açıkça görülmek- tedir. Varyasyonun genişliği 06:00 hasadında \%3.507.25, 08:00 hasadında \%3.15-5.95, 10:00 hasadında $\% 3.55-6.45,12: 00$ hasadında \%3.45-6.80, 14:00 hasadında \%3.10-6.10, 16:00 hasadında \%3.10-6.70, 18:00 hasadında \%3.65-6.00 ve 20:00 hasadında \%2.95-7.30 arasında bulunmuştur.

Çizelge 5. Hasat saatlerine göre Coridothymus capitatus L. genotiplerinde uçucu yağ oranına (\%) ilişkin bazı istatistiksel değerler Table 5. Some harvest-hour based statistical values for essantial oil rate (\%) in coridothymus capitatus L. genotypes

\begin{tabular}{cccccccccc}
\hline Hasat Saatleri & Genotip Sayısı & Min. & Max. & Ort. & Varyans & Standart Sapma & Sx & 0.9212 & 0.1842 \\
\hline $06: 00$ & 25 & 3.50 & 7.25 & 4.99 & 0.8487 & 18.4543 & 0.1339 & 13.7490 \\
\hline $08: 00$ & 25 & 3.15 & 5.95 & 4.87 & 0.4483 & 0.6696 & 0.7849 & 0.1570 & 16.3652 \\
\hline $10: 00$ & 25 & 3.55 & 6.45 & 4.80 & 0.6160 & 0.1529 & 16.3722 \\
\hline $12: 00$ & 25 & 3.45 & 6.80 & 4.67 & 0.5846 & 0.7646 & 0.8724 & 0.1745 & 18.4214 \\
\hline $14: 00$ & 25 & 3.10 & 6.10 & 4.73 & 0.7612 & 0.7617 & 0.1523 & 16.8960 \\
\hline $16: 00$ & 25 & 3.10 & 6.70 & 4.51 & 0.5801 & 0.6365 & 0.1273 & 14.0946 \\
\hline $18: 00$ & 25 & 3.65 & 6.00 & 4.52 & 0.4051 & 0.9572 & 0.1914 & 19.7859 \\
\hline $20: 00$ & 25 & 2.95 & 7.30 & 4.84 & 0.9163 & & & &
\end{tabular}



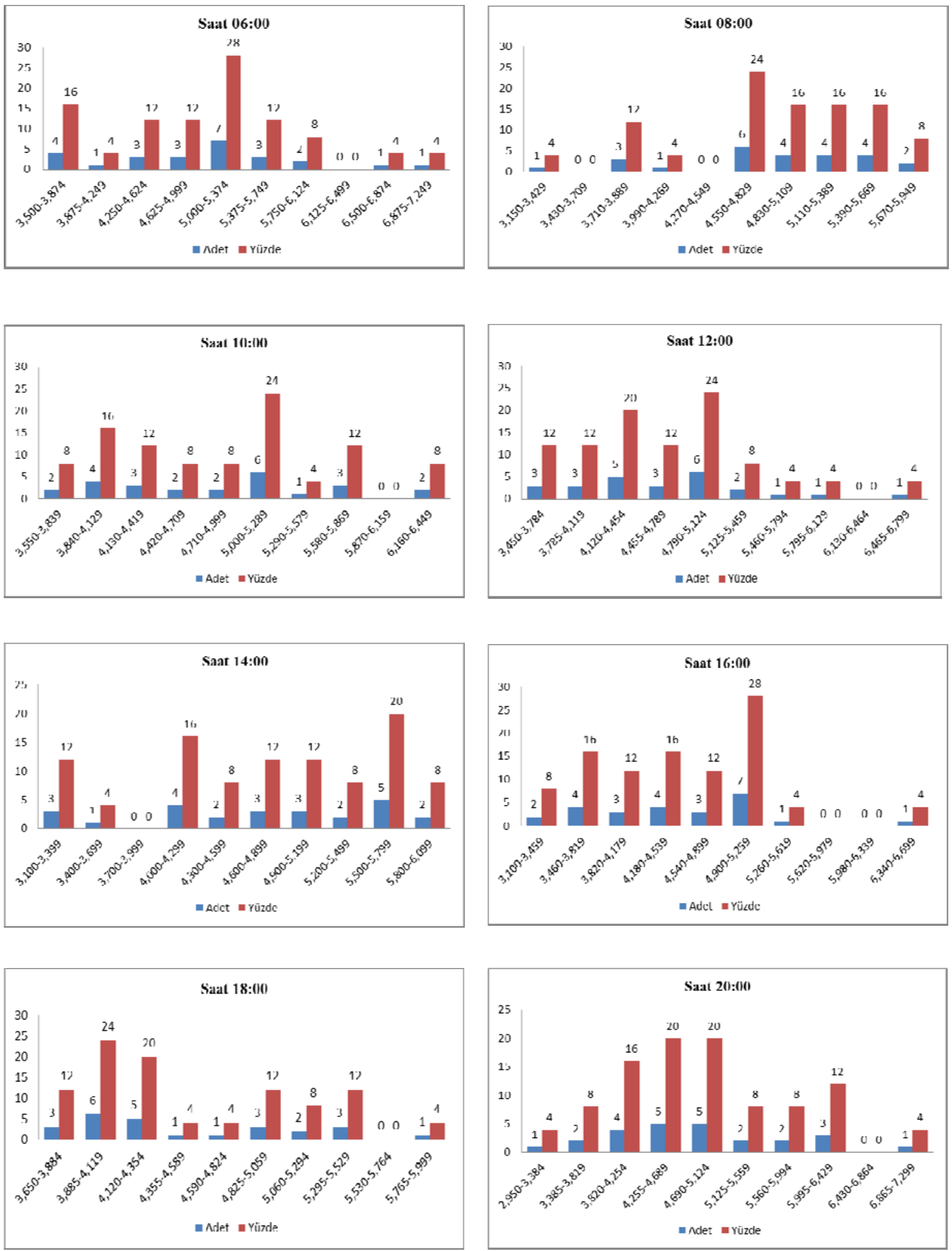

Şekil 1. Hasat saatlerine göre uçucu yağ oranlarının frekans dağılımı

Figure 1. Frequency distribution of the essential oil content on the harvest-hour based 
Hasat saatlerine göre uçucu yağ oranlarının frekans dağılımlarının bulunduğu Şekil 1 incelendiğinde, minimum ve maksimum değerdeki bitki sayılarının oldukça az, buna karşın ortalamaya yakın değerlerin büyük bir orana sahip olduğu belirlenmiştir. Saat 06:00 hasadında uçucu yağ oranının ortalama değeri \%4.990 olup, frekans dağılımında \%4.250-6.124 arasında değişen değerler tüm uçucu yağ oranlarının \%76'sını oluşturmuştur. Saat 08:00 hasadında ise ortalama değer \%4.870 olmuş ve tüm genotipler \%4.55-5.949 aralığında ve bu değer tüm genotiplerin \%80'ini kapsamıştır. Saat 10:00 hasadında 25 genotipin ortalama değeri \%4.800 bulunurken, frekans dağılımında \%3.550-5.289 arasındaki genotiplerin oranı tüm genotiplerin oranının \%76'sını teşkil etmiştir. Saat 12:00 hasadında ortalama uçucu yağ oranı \%4.670 ve tüm genotiplerin \%80'ni \%3.450-5.124 aralığında yer almıştır. Saat 14:00 hasadı \%4.730 ortalama uçucu yağ oranı içerirken, genotiplerin \%84'ü \%4-6.099 arasında frekans dağılımı göstermiştir. Saat 16:00 hasadında ortalama değer \%4.510 ile önceki hasat saatlerine göre oldukça düşerken, tüm genotiplerin frekans dağılımının \%3.460-5.259 aralığında bulunduğu ve \%84'lük bir orana ulaştığı dikkati çekmiştir. Saat 18:00 hasadında ortalama değer \%4.520 ile bir önceki hasat saati değerine yakın bulunurken, \%3.650-4.354 aralığı tüm değerlerin \%56'sını oluşturmuştur. Saat 20:00 hasadın- da ortalama uçucu yağ oranı \%4.840 değeri ile bir önceki hasat saatine göre artma eğilimi gösterirken, \%3.820-6.429 aralığı tüm genotiplerin \%84'nü temsil etmiştir (Şekil 1).

Bitkiler gün içerisinde değişen farklı iklim faktörlerinin etkisi altında bulunduğu için, bu süreçte yapılan hasatlarda büyük bir varyasyonun oluştuğu saptanmıştır. Bu durum diurnal varyabilitenin varlığına işaret etmektedir. Buna göre bitkinin hasadının rastgele herhangi bir saatte yapılamayacağı ve uçucu yağ oranının en yüksek noktaya ulaştığı saatin belirlenmesi önemlidir. Ortalama uçucu yağ oranlarının yer aldığı Çizelge 5 incelendiğinde, Coridothymus capitatus L. genotiplerinin saat 06:00 hasadında \%4.99 ile en yüksek uçucu yağ oranına sahip olduğu, bu hasat saatinden, saat 12:00 hasadına kadar uçucu yağ oranlarında belirgin bir azalmanın görüldüğü, saat 12 hasadında uçucu yağ oranın ortalama \%4.67'ye düştüğü ve bu saatten sonraki hasat da ise biraz yükselmeye başladığı (\%4.73), ancak saat 16:00 hasadında, uçucu yağ oranının tekrar düştüğü ve gün içerisindeki sıcaklık değerinin en yüksek, oransal nem değerinin ise en düşük (sırasıyla $40.29^{\circ} \mathrm{C}$ ve \%22) olduğu saatte \%4.51 ile en düşük ortalama uçucu yağ oranının olduğu saptanmıştır. Bu durum gün içerisindeki sıcaklık ve uçucu yağ oranı arasındaki değişimin verildiği Şekil 2'de açıkça görülmektedir.

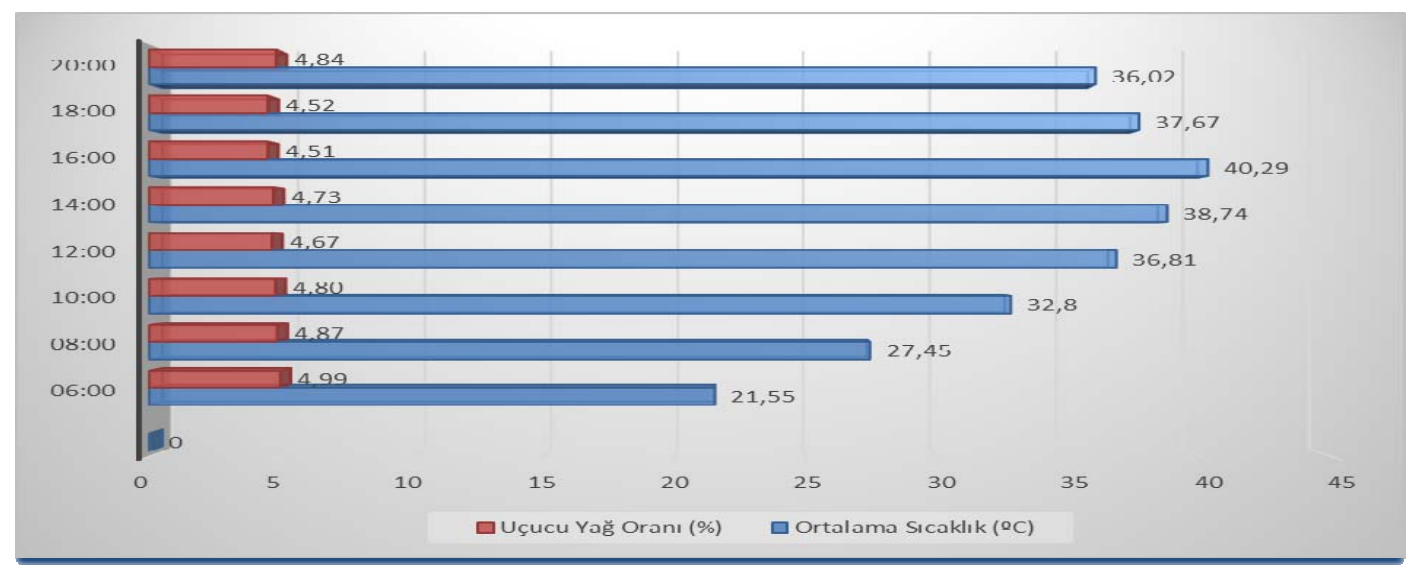

Şekil 2. Coridothymus capitatus L. yapraklarına uçucu yağın diurnal varyabilitesi (\%)

Figure 2. Diurnal variability of essential oil in the leaves of Coridothymus capitatus L.

Aynı genotiplerle farklı hasat saatlerinde yapılan biçimlerden elde edilen uçucu yağ oranlarının bazı istatistiksel değerleri Çizelge $6^{\prime}$ da verilmiştir. Çizelge incelendiğinde genotiplere göre 8 farklı hasat saatinde elde edilen uçucu yağ oranlarının genotipler arasında farklılık gösterdiği ve büyük bir varyasyonun bulunduğu saptanmıştır. Genotipler arasında en düşük uçucu yağ oranının \%2.95 ile 10 nolu genotipte ve en yüksek uçucu yağ oranının \%7.30 ile 20 nolu genotipte olduğu belirlenmiştir. Ortalama uçucu yağ oranları dikkate alındığında, en düşük ortalama değerin \%3.79 ile 14 nolu genotipte bulunduğu, en yüksek oranın ise $\% 6.54$ ile 20 nolu genotipte olduğu, bunu \%5.34 ile 22 nolu, \%5.28 ile 16 nolu ve \%5.24 ile 5 nolu genotiplerin izlediği tespit edilmiştir (Şekil 3). 
Çizelge 6. Coridothymus capitatus L. genotiplerinde uçucu yağ oranına (\%) ilişkin bazı istatistiksel değerler Table 6. Some statistical values for essential oil rate (\%) of Coridothymus capitatus L.

\begin{tabular}{|c|c|c|c|c|c|c|c|}
\hline Genotip No & Min. & Max. & Ort. & Varyans & Standart Sapma & Sx & CV \\
\hline 1 & 3.15 & 4.85 & 3.869 & 0.2928 & 0.5411 & 0.1913 & 13.9870 \\
\hline 2 & 4.15 & 5.80 & 5.006 & 0.3239 & 0.5691 & 0.2012 & 11.3680 \\
\hline 3 & 3.65 & 6.00 & 4.994 & 0.5075 & 0.7124 & 0.2519 & 14.2650 \\
\hline 4 & 4.00 & 5.95 & 5.038 & 0.4770 & 0.6906 & 0.2442 & 13.7097 \\
\hline 5 & 4.45 & 5.65 & 5.244 & 0.1739 & 0.4170 & 0.1474 & 7.9522 \\
\hline 6 & 3.45 & 6.15 & 4.944 & 0.6067 & 0.7789 & 0.2754 & 15.7560 \\
\hline 7 & 3.25 & 5.50 & 4.381 & 0.4814 & 0.6938 & 0.2453 & 15.8361 \\
\hline 8 & 4.00 & 4.80 & 4.363 & 0.0705 & 0.2656 & 0.0939 & 6.0879 \\
\hline 9 & 3.10 & 5.30 & 4.656 & 0.4760 & 0.6899 & 0.2439 & 14.8177 \\
\hline 10 & 2.95 & 5.75 & 4.075 & 0.8764 & 0.9362 & 0.3310 & 22.9737 \\
\hline 11 & 3.70 & 5.70 & 4.544 & 0.5232 & 0.7233 & 0.2557 & 15.9187 \\
\hline 12 & 3.75 & 4.60 & 4.194 & 0.1296 & 0.3600 & 0.1273 & 8.5841 \\
\hline 13 & 3.80 & 4.65 & 4.137 & 0.0948 & 0.3079 & 0.1089 & 7.4424 \\
\hline 14 & 3.25 & 4.40 & 3.794 & 0.1182 & 0.3438 & 0.1215 & 9.0612 \\
\hline 15 & 3.55 & 4.35 & 4.000 & 0.0493 & 0.2220 & 0.0785 & 5.5501 \\
\hline 16 & 4.35 & 6.85 & 5.281 & 0.6564 & 0.8102 & 0.2864 & 15.3406 \\
\hline 17 & 3.70 & 5.60 & 4.913 & 0.3798 & 0.6163 & 0.2179 & 12.5455 \\
\hline 18 & 4.10 & 6.25 & 5.156 & 0.5046 & 0.7104 & 0.2511 & 13.7765 \\
\hline 19 & 4.65 & 5.65 & 5.188 & 0.0870 & 0.2949 & 0.1043 & 5.6848 \\
\hline 20 & 5.75 & 7.30 & 6.544 & 0.3275 & 0.5722 & 0.2023 & 8.7448 \\
\hline 21 & 3.95 & 5.30 & 4.775 & 0.1893 & 0.4351 & 0.1538 & 9.1114 \\
\hline 22 & 4.75 & 6.40 & 5.337 & 0.3427 & 0.5854 & 0.2070 & 10.9674 \\
\hline 23 & 3.60 & 5.45 & 4.825 & 0.3464 & 0.5886 & 0.2081 & 12.1986 \\
\hline 24 & 3.75 & 5.40 & 4.594 & 0.4425 & 0.6652 & 0.2352 & 14.4800 \\
\hline 25 & 4.15 & 5.40 & 4.669 & 0.2421 & 0.4920 & 0.1740 & 10.5389 \\
\hline
\end{tabular}

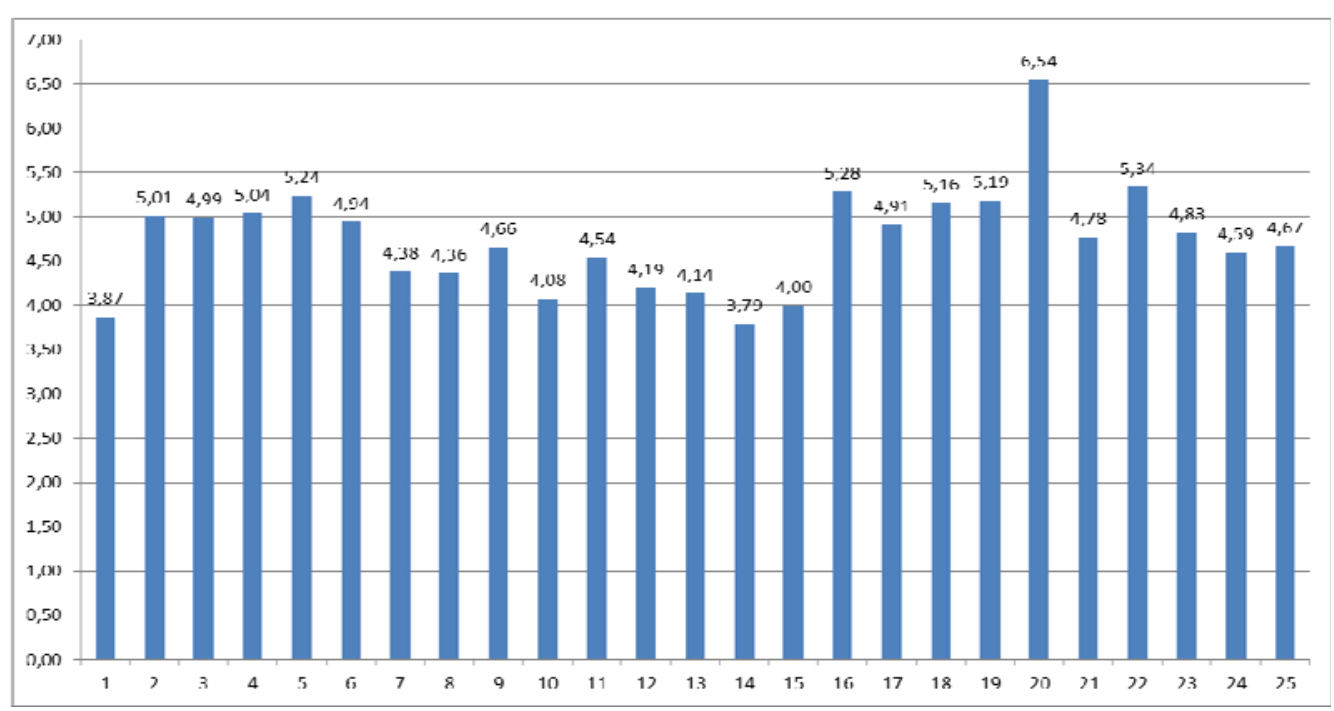

Şekil 3. Coridthymus capitatus L. genotiplerinin uçucu yağ oranları (\%)

Figure 3. Essential oil rates of Coridothymus capitatus L. genotypes (\%) 
Gün içerisinde yapılan 8 hasat saatine göre genotipler içerisinde en yüksek uçucu yağ oranlarının elde edildiği 20, 22, 16 ve 5 nolu genotiplerde yapılan uçucu yağ bileşenlerine ait sonuçlar Çizelge 7'de sunulmuştur. Coridothymus capitatus L. Genotiplerinin uçucu yağında 12 farklı bileşen tespit edilmiştir. İncelenen bu genotiplerde ana bileşenin karvakrol olduğu ve oranının \%42.87-87.38 arasında değiştiği belirlenmiştir. Diğer önemli bileşenlerin $\gamma$-terpinen $\% 1.47-12.46$, linalol \%0.86-2.64 ve timol \%0.31-29.23 olduğu bulunmuştur (Şekil 4). Ana bileşen olan karvakrolün incelenen genotiplerde en yüksek değerine saat 14 hasadında ulaştığı saptanmıştır (Çizelge 7). Ancak uçucu yağ bakımından en yüksek değerin elde edildiği saat 6:00 hasadında karvakrol oranlarının genellikle en yüksek değere yakın olduğu tespit edilmiştir.

Uçucu yağ içeren bitkilerde iklim, çevre, topografik koşullar ile genetik yapı ve bireysel varyabilite olarak adlandırılan morfogenetik, ontogenetik ve diurnal varyabiliteye göre uçucu yağ oranı değişim göstermektedir (Ceylan, 1995; Arabacı ve ark., 2012).

Coridothymus capitatus L. bitkisi uçucu yağ ve fenolik bileşikler içermesi nedeniyle değerlidir (Başer, 1995). Çalışmamızda uçucu yağ oranı \%2.95-7.30 arasında olup hasat saatlerine göre ortalama \%4.514.99 arasında ve genotiplere göre ortalama \%3.79-6.54 arasında varyasyon göstermiştir.

Bitkide uçucu yağ oranının; Özek ve ark (1995) $\% 0.45-2.7$, Baydar ve ark (1999) ortalama \%2.46, Baytop (1999) \%0.4-1.0, Skoula ve Grayer (2005) \%2.74.6 ve Diri (2006) \%1.98-2.56, Economou ve ark (2011) tam çiçeklenme döneminde bitkide uçucu yağ oranının \%3.7-5.6 arasında değiştiğini ve ortalama değerin \%4.4 olduğunu, Arabacı ve ark (2012) ise uçucu yağ oranının en yüksek orana tam çiçeklenme döneminde ulaştığını değerinin \%3.0-6.40 arasında değiştiğini ve ortalama uçucu yağ oranının \%4.60 olduğunu kaydetmişlerdir. Elde ettiğimiz uçucu yağ değeri Arabacı ve ark (2012) ile uyumlu ve diğer araştırıcıların değerlerinden oldukça yüksektir.

Economou ve ark., (2011) Coridothymus capitatus L. bitkisinde uçucu yağın en önemli bileşenini karvakrolün oluşturduğunu oranının \%82.87-90.89 arasında değiştiğini ve ortalama değerinin \%87.54 olduğunu belirtmişlerdir. Çalışmamızda karvakrol en önemli bileşen olarak belirlenmiş ve değeri \%42.8787.38 arasında yer almıştır. Elde ettiğimiz sonuçlar araştırıcıların sonuçlarından düşük bulunmuştur. Bu durum genotipik, çevresel ve iklimsel farklılıklardan kaynaklanmış olabilir.

Gün içerisinde uçucu yağ oranı ve bileşiminde meydana gelen değişimlere ilişkin Coridothymus capitatus L. bitkisi ile yapılmış önceki çalışmaların taranması sırasında benzer çalışmalara rastlanmamıştır. Bu nedenle Türkiye'de kekik adı altında isimlendirilerek ticareti yapılan diğer türlerde yapılmış diurnal varyabilite çalışmaları incelenmiştir. Yaldız ve ark., (2005) Çukurova ekolojik koşullarında Origanum onites L. bitkisinde bir yıl boyunca her hafta ve gün içerisinde $08: 00,12: 00$ ve $16: 00$ saatlerinde yaptıkları hasatlarda, öğleden sonra saat 16:00'da yapılan hasatta en yüksek ortalama uçucu yağ oranının (\%0.87) alındığını bildirmişlerdir. Tonçer ve ark (2009) Diyarbakır ekolojik koşullarında Origanum onites L. bitkisinde bir gün içerisinde altı hasat saatinde (06:00, 10:00, 12:00, 16:00, 20:00 ve 24:00) uçucu yağ bileşenlerinin değişimini incelemek üzere yaptıkları çalışmada en yüksek karvakrol oranının saat 10:00 (\%48.13) hasadında olduğunu saptamışlardır. Kaya ve ark (2013a) Hatay ekolojik koşullarında Thymbra spicata L. bitkisinde bir gün boyunca birer saat aralıklarla yaptıkları hasat ile uçucu yağ oranının taze herba ve kuru herba örneklerinde sabah 05:00'te yapılan hasatlarda en yüksek değeri verdiğini (sırasıyla \%0.90 ve \%3.04) kaydetmişlerdir. Uçucu yağın en önemli bileşenini oluşturan karvakrolün en düşük değerini taze herbada \%51.89 ile saat 13:00, kuru herbada \%51.25 ile saat 14:00 hasatlarında olduğu ve en yüksek değerlerinin ise taze herbada \%66.38 ile gece saat 03:00 ve kuru herbada \%59.30 ile sabah 09:00 hasatlarında bulunduğunu tespit etmişlerdir. Thymus vulgaris L. bitkisindeki diurnal varyabiliteyi belirlemek amacıyla yine Kaya ve ark (2013b) tarafından yapılan başka bir çalışmada birer saat aralıklarla gün içerisinde 06:00-17:00 saatleri arasında yaptıkları hasatlarda drog yaprak örneklerinde en yüksek uçucu yağ oranının saat 06:00 hasadı (\%2.20) ile elde edildiğini, gün içerisinde uçucu yağ oranının giderek azaldığını ve en düşük değere saat 17:00 hasadı (\%1.65) ile ulaşıldığını belirlemişlerdir. Aynı ç alışmada uçucu yağın en önemli bileşeni olan timolün sabah 07:00 hasadında en yüksek değeri (\%46.71) verdiğini, en düşük değerin ise saat 15:00 hasadında (\%26.81) olduğunu tespit etmişlerdir. Bu çalışmalar genel olarak değerlendirildiğinde; en yüksek uçucu yağ oranının sabah saatlerinde yapılan hasatlardan elde edildiği söylenebilir. 
Doğal Yayılış Gösteren Coridothymus capitatus L. Genotiplerinde Diurnal Varyabilitenin Verim ve Kaliteye Etkisi

Çizelge 7. Coridothymus capitatus L.'un bazı genotiplerinde uçucu yağ bileşenler

Table 7. Essential oil components in some Coridothymus capitatus L. Genotypes

\begin{tabular}{|c|c|c|c|c|c|c|c|c|c|c|c|c|c|}
\hline Gen. No & Saat & a. pinen & $\beta$-pinen & Limonen & $\gamma$-terpinen & p-simen & a-tuyon & Linalil asetat & Linalol & Cis-sabinen hidrat & Bomeol & Timol & Karvakrol \\
\hline \multirow{8}{*}{5} & 6 & 0.60 & 1.36 & 0.22 & 7.47 & 0.25 & 0.19 & 1.06 & 1.76 & 0.66 & 0.06 & 0.33 & 70.48 \\
\hline & 8 & 0.45 & 1.51 & 0.27 & 7.92 & 0.30 & 0.23 & 0.81 & 2.05 & 0.66 & 0.12 & 0.50 & 68.62 \\
\hline & 10 & 0.68 & 1.58 & 0.27 & 8.41 & 0.32 & . & 0.82 & 2.64 & 0.63 & 0.17 & 0.36 & 69.73 \\
\hline & 12 & 0.57 & 1.27 & 0.22 & 6.81 & 0.21 & 0.21 & 0.86 & 1.94 & 0.67 & 0.11 & 0.35 & 72.93 \\
\hline & 14 & 0.83 & 1.52 & 0.22 & 7.58 & 0.25 & 0.16 & 0.95 & 1.44 & 0.65 & 0.09 & 0.44 & 69.96 \\
\hline & 16 & 0.87 & 1.74 & 0.30 & 9.33 & 0.26 & 0.19 & 1.07 & 1.77 & 0.71 & 0.07 & 0.31 & 65.71 \\
\hline & 18 & 0.86 & 1.63 & 0.25 & 8.61 & 0.28 & 0.21 & 0.73 & 2.19 & 0.67 & 0.12 & 0.35 & 68.46 \\
\hline & 20 & 0.90 & 1.81 & 0.24 & 8.51 & . & 0.22 & 0.87 & 2.00 & 0.70 & 0.12 & 0.33 & 65.11 \\
\hline \multirow{8}{*}{16} & 6 & 0.39 & 0.98 & 0.20 & 3.29 & 0.26 & 0.14 & 0.78 & 0.86 & 0.74 & 0.10 & 0.38 & 78.82 \\
\hline & 8 & 0.68 & 1.44 & 0.26 & 5.99 & 0.41 & 0.19 & 0.74 & 1.39 & 0.67 & 0.06 & 23.32 & 47.69 \\
\hline & 10 & 0.21 & 1.02 & 0.19 & 4.22 & 0.29 & 0.15 & 0.83 & 1.38 & 0.76 & 0.09 & 0.41 & 76.63 \\
\hline & 12 & 0.91 & 1.31 & 0.40 & 5.53 & 0.35 & 0.10 & 0.92 & 1.26 & 0.71 & 0.07 & 29.23 & 42.87 \\
\hline & 14 & 0.32 & 0.90 & 0.18 & 4.48 & 0.51 & 0.21 & 0.69 & 1.69 & 0.75 & 0.07 & 0.45 & 75.60 \\
\hline & 16 & 0.53 & 1.17 & 0.21 & 9.11 & 0.30 & 0.14 & 0.95 & 2.30 & 0.74 & 0.09 & 0.33 & 62.88 \\
\hline & 18 & 0.87 & 1.52 & 0.27 & 7.90 & 0.42 & 0.13 & 0.73 & 2.01 & 0.68 & 0.09 & 0.36 & 66.19 \\
\hline & 20 & 0.36 & 1.10 & 0.19 & 7.65 & 0.46 & 0.21 & 0.73 & 1.47 & 0.72 & 0.09 & 0.36 & 70.39 \\
\hline \multirow{8}{*}{20} & 6 & 0.20 & 1.03 & 0.19 & 5.34 & 0.15 & 0.19 & 0.56 & 1.34 & 0.66 & 0.05 & 0.42 & 79.27 \\
\hline & 8 & . & 0.32 & 0.18 & 1.47 & 0.13 & 0.20 & 0.52 & 1.71 & 0.70 & 0.09 & 0.41 & 87.38 \\
\hline & 10 & 0.47 & 1.30 & 0.18 & 5.12 & 0.10 & 0.10 & 0.51 & 1.10 & 0.49 & 0.14 & 0.81 & 61.69 \\
\hline & 12 & 0.38 & 1.15 & 0.22 & 4.71 & 0.11 & 0.15 & 0.45 & 0.88 & 0.52 & 0.08 & 0.66 & 60.81 \\
\hline & 14 & 0.29 & 0.99 & 0.17 & 5.60 & 0.13 & 0.14 & 0.48 & 1.32 & 0.68 & 0.04 & 0.38 & 79.30 \\
\hline & 16 & 0.89 & 1.78 & 0.24 & 7.08 & 0.16 & 0.12 & 0.59 & 1.14 & 0.62 & 0.05 & 0.38 & 74.63 \\
\hline & 18 & 0.86 & 1.62 & 0.22 & 6.02 & 0.40 & 0.14 & 0.85 & 1.53 & 0.75 & 0.06 & 0.31 & 71.75 \\
\hline & 20 & 1.08 & 1.84 & 0.24 & 6.99 & 0.53 & 0.09 & 0.57 & 1.10 & 0.61 & 0.05 & 0.41 & 71.21 \\
\hline \multirow{8}{*}{22} & 6 & . & 0.86 & 0.19 & 5.03 & 0.57 & 0.24 & 0.54 & 1.56 & 0.79 & 0.11 & 0.48 & 69.88 \\
\hline & 8 & 0.45 & 1.37 & 0.22 & 10.86 & 0.68 & 0.13 & 0.48 & 0.88 & 0.65 & 0.05 & 0.44 & 64.94 \\
\hline & 10 & 0.35 & 1.30 & 0.21 & 10.33 & 0.70 & 0.09 & 0.49 & 1.06 & 0.67 & 0.05 & 0.40 & 66.94 \\
\hline & 12 & 0.56 & 1.48 & 0.26 & 11.26 & 0.63 & 0.13 & 0.47 & 1.07 & 0.62 & 0.06 & 0.41 & 66.48 \\
\hline & 14 & 0.45 & 1.21 & 0.19 & 6.65 & 0.23 & 0.14 & 0.51 & 1.46 & 0.74 & 0.07 & 0.41 & 71.58 \\
\hline & 16 & 0.70 & 1.75 & 0.20 & 7.44 & 0.17 & 0.15 & 0.65 & 1.17 & 0.72 & 0.04 & 0.40 & 66.45 \\
\hline & 18 & 0.76 & 1.97 & 0.23 & 7.66 & 0.12 & 0.20 & 0.53 & 1.10 & 0.78 & 0.09 & 0.37 & 70.16 \\
\hline & 20 & 0.83 & 1.91 & 0.29 & 12.46 & 0.75 & 0.46 & 0.66 & 1.34 & 0.73 & . & 0.44 & 72.13 \\
\hline
\end{tabular}

Uçucu Yağ Bileşenleri

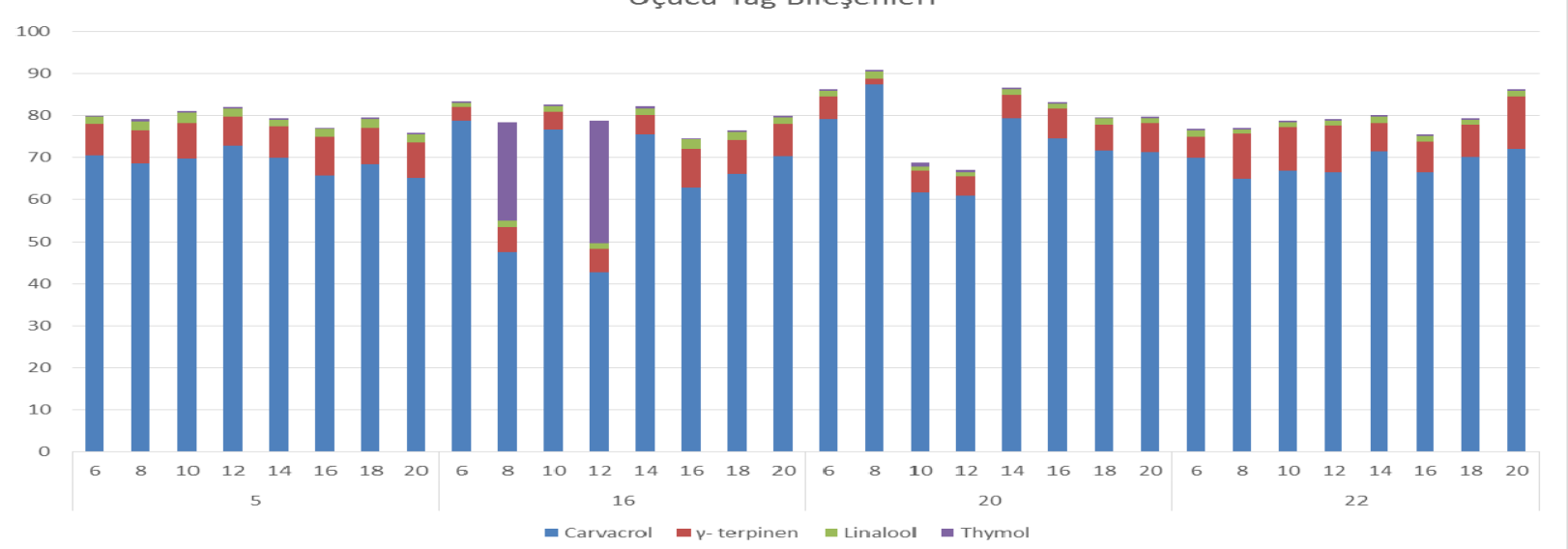

Şekil 4. Coridothymus capitatus L. genotiplerinde uçucu yağ bileşenlerinin diurnal varyabilitesi

Figure4. Diurnal veriabilities of essential oil compounds of Coridothymus capitatus L. genotypes 


\section{SONUÇ}

Coridothymus capitatus L. bitkisi Aydın yöresinde yoğun olarak toplanıp ticareti yapılmaktadır. Bitki toplayıcılığı ekolojik dengenin bozulmasına, biyolojik çeşitliliğin azalmasına ve yöreden yöreye hatta bitkiden bitkiye değişen heterojenlik nedeniyle kaliteye olumsuz etkilemektedir. Ticarette yer alan bitkilerin toplayıcılığından vazgeçilerek kültüre alınması başta gen kaynaklarının korunması açısından oldukça önemlidir. Diğer taraftan hasat için uygun dönem ve saatinin belirlenmesi de kaliteye büyük katkı yapmaktadır.

Aydın ilinde doğal yayılış alanlarından aşırı ve kontrolsüz olarak toplanmakta olan Coridothymus capitatus L. bitkisinin doğadaki toplamalarında en uygun fenolojik dönemlerin belirlenmesine yönelik olarak yaptığımız önceki çalışmamızda tam çiçeklenme döneminin yüksek uçucu yağ oranının elde edil-

\section{KAYNAKLAR}

Açıkgöz, N., M.E. Akkaş, A. F. Moghaddam ve K. Özcan, 1994 PC’ler için Veri Tabanı Esaslı Türkçe İstatistik Paketi: TARIST, I. Tarla Bitkileri Kongresi, 24-28.04.1994, İzmir, C:2, 264-267.

Anonim, 2012. http//yabanicicek.com/ Coridothymus capitatus_ekbilgi.php

Arabacı, O., N.G. Öğretmen, D.F. Aslan ve İ.İ. Özcan, 2012. Coridothymus capitatus (L.) Genotiplerinde Ontogenetik Varyabilite, Tibbi ve Aromatik Bitkiler Sempozyumu, 13-15 Eylül 2012, Tokat, 88-99.

Başer, K.H.C., 1995. Essential Oils From Aromatic Plants Which are Used as Herbal Tea in Turkey, In: Flavours, Fragrances and Essential Oils Proceedings of the 13 th International Congress of Flavours, Fragrances and Essential Oils, İstanbul, 15-19 October, 67-79.

Baydar, H., R.A.Marquard ve T. Karadoğan, 1999. Isparta Yöresinden Toplanarak İhracat Edilen Bazı Önemli Origanum, Coridothymus, Thymbra ve Salvia Türlerinin Uçucu Yağ Verim ve Kompozisyonu. Türkiye 3. Tarla Bitkileri Kongresi, 15-18 Kasım 1999, Adana, Cilt II, End. Bitkileri, 416-420.

Baytop, T., 1999. Türkiye'de Bitkiler ile Tedavi, Nobel Tip Kitabevleri, 254.

Bown, D., 1995. Encyclopaedia of Herbs and Their Uses. Dorling Kindersley, London, ISBN 0-7513-020-31.

Ceylan, A., 1995. Tibbi Bitkiler I, EÜ. Zir. Fak. Yay No:312, 107 133.

Davis, P.H., 1982. Flora of Turkey and the East Aegean Islands, Vol 7., Edinburgh Univ. Pres, Edinburg, 382.

Diri, M., 2006. Coridothymus capitatus (L) Reichb. Uçucu Yağının Analizi, $\mathrm{Su}$ ve Etanol Ekstraktlarının Antioksidant Aktivitelerinin Belirlenmesi, Muğla Üniv. Fen Bil. Enst. Kimya ABD, YL Tezi, 101.

Economou, G., G. Panagopoulos, P. Tarantilis, D. Kalivas, V. Kotoulas, I.S. Travlos, M. Polysiou and A. Karamanos, 2011. Variability in Essential Oil Content and Composition of Origanum hirtum L., Origanum onites L., Coridothymus capitatus (L) and Satureja thymbra L. Populations from the Greek Island Ikaria, Industrial Crops and Products 33, 236-241. mesi açısından uygun olduğu belirlenmiştir. Mevcut çalışmamızda da bu noktadan hareket edilerek yapılan gün içerisindeki en uygun hasat saati saptanmış ve sabah erken saatlerde uçucu yağ oranı ve bileşenlerinin günün diğer saatlerine göre daha yüksek olduğu kaydedilmiştir. Ayrıca güneşin doğuşu ve batışı arasında geçen sürede drog herba oranını etkileyen önemli bir farklıı̆̆ın olmadığı belirlenmiştir.

Floramızdaki gen kaynaklarının korunması için genotiplerin genetik yapılarından kaynaklanan morfolojik ve kalite özelliklerinin belirlenerek ortaya konması gelecekte yapılacak kültüre alma çalışmalarında dikkate alınması gerekmektedir. Bu çalışmada incelenen popülasyon içerisinde diurnal varyabiliteye bağlı olarak genotipik farklılıklar ortaya konmuş ve 20 , 22,16 ve 5 nolu genotiplerin yüksek uçucu yağ içerikleri bakımından gelecekte yapılacak çalışmalar için ümitvar genotipler olduğu saptanmıştır.

Gören, A.C., G. Bilsel, M. Bilsel, H. Demir ve E.E. Kocabaş, 2003. Analysis of Essential Oil of Coridothymus capitatus (L.) and Its Antibacterial and Antifungal Activity. P 687-690.

Kaya, D.A., M. Arslan, M. Inan and S. Baskaya, 2013a. Diurnal Changes on Content and Composition of Thymbra spicata L. Essential Oil, Research Journal of Biological Sciences 8(1):6-10.

Kaya, D.A., M. Arslan, M. Inan and L.C. Rusu, 2013b. Effects of Harvesting Hour on Essential Oil Content and Composition of Thymus vulgaris, Farmacia, Vol.61, 1194-1203.

Özek, T., F. Demirci ve K.H.C. Başer, 1995. Composition of the Essential Oil of Coridothymus capitatus (L.) Reichb. From Turkey, Jour. of Essential Oil. Res. 7:3, 309-312.

Polunin, O. and A. Huxley, 1987. Flowers of the Mediterranean. Hogarth Pres ISBN 0-7012-0784-1.

Seçmen, Ö., Y. Gemici, G. Görk, L. Bekat ve E. Leblebici, 1995. Tohumlu Bitkiler Sistematiği, Ege Üniv. Fen Fak. Kitaplar Serisi No:116, 279 s., İzmir.

Sezik, E. ve E. Yeşilada, 1999. Uçucu Yağ Taşıyan Türk Halk İlaçları. Essential Oils, Ed. N. Kırımer, A. Mat, 98-131 s., Eskişehir.

Skoula, M and R.J. Grayer, 2005. Volatile Oils of Coridothymus capitatus, Satureja, Thymbra, Satureja spinosa and Thymbra calostachya (Lamiaceae) from Crete, Flavour Fragr. J. 20; 573. 576.

Toncer, O., S. Karaman, S.K1z1l and E. Diraz, 2009. Changes in Essential Oil Composition of Oregano (Origanum onites L.) due to Diurnal Variations at Different Development Stages, Not. Bot. Hort. Agrobot. Cluj. 37 (2), 177-181.

Vokou, D., S. Vareltzidou and P. Katinakis, 1993. Effects of Aromatic Plants on Potato Storage-Sprout Suppression and Antimicrobiyal Activity, Agric.Ecosyst. Environ. 47,223-235.

Wichtl, M., 1971. Die Pharmakognostisch-Chemische Analyse Akad. Verlagsgesellschaft, Frankfurt, 479 .

Yaldiz, G., N. Sekeroglu, M. Ozguven and M. Kirpik, 2005. Seasonal and Diurnal Variability of Essential Oil and Its Components in Origanum onites L. Grown in the Ecological Conditions of Çukurova, Grasas y Aceites Vol.56. Fasc. 4, 254-258.

Zeybek, N., U.Zeybek, 1994. Farmasötik Botanik. Ege Üniv. Ecz. Fak. Yay No.2, 370 s., İzmir. 